\title{
Vascular Sap Proteomics: Providing Insight into Long-Distance Signaling during Stress
}

\author{
Philip Carella, Daniel C. Wilson, Christine J. Kempthorne and Robin K. Cameron* \\ Department of Biology, McMaster University, Hamilton, ON, Canada
}

The plant vascular system, composed of the xylem and phloem, is important for the transport of water, mineral nutrients, and photosynthate throughout the plant body. The vasculature is also the primary means by which developmental and stress signals move from one organ to another. Due to practical and technological limitations, proteomics analysis of xylem and phloem sap has been understudied in comparison to accessible sample types such as leaves and roots. However, recent advances in sample collection techniques and mass spectrometry technology are making it possible to comprehensively analyze vascular sap proteomes. In this mini-review, we discuss the emerging field of vascular sap proteomics, with a focus on recent comparative studies to identify vascular proteins that may play roles in long-distance signaling and other

\section{OPEN ACCESS}

Edited by:

Hanjo A. Hellmann,

Washington State University, USA

Reviewed by:

Abu Hena Mostafa Kamal, University of Texas at Arlington, USA Elisabeth Jamet, Laboratoire de Recherche en Sciences Végétales, France

*Correspondence:

Robin K. Cameron rcamero@mcmaster.ca

Specialty section:

This article was submitted to Plant Proteomics,

a section of the journal Frontiers in Plant Science

Received: 23 March 2016 Accepted: 28 April 2016 Published: 12 May 2016

Citation: Carella P, Wilson DC, Kempthorne CJ and Cameron RK (2016) Vascular Sap

Proteomics: Providing Insight into Long-Distance Signaling during Stress. Front. Plant Sci. 7:651. doi: 10.3389/fpls.2016.00651 processes during stress responses in plants.

Keywords: abiotic stress, biotic stress, long-distance signaling, phloem, proteomics, xylem

\section{INTRODUCTION}

Plants are unable to relocate during unfavorable environmental conditions and instead rely on intricate signaling pathways that work at the local and systemic level to withstand stress. At the local level, stress-related signals move cell-to-cell through plasmodesmata (symplastic) or diffuse through the extracellular space (apoplastic). These communication processes are effective for signaling between neighboring cells or adjacent tissues, but are insufficient for systemic communication between organs (Lucas et al., 2013). For long-distance movement between distant tissues, macromolecules often access the plant vasculature; a system of specialized transport conduits connecting all organs of the plant.

\section{The Plant Vascular System: Sharing Resources and Information}

The xylem vessels and phloem sieve tubes of the plant vascular system connect above- and belowground organs, allowing vascular plants to draw from two distinct resource pools. The xylem provides an avenue for the unidirectional transport of water and mineral nutrients (xylem sap) from roots to aerial tissues that is driven by the transpiration stream. In contrast, the phloem allows for the bidirectional movement of photosynthate and other macromolecules throughout the plant, from areas of synthesis or excess (source) to areas of use (sink) such as storage tissues or zones of active growth. The fluid within the phloem is known as phloem sap, and its movement is thought to be driven by a hydrostatic pressure gradient along sieve tubes according to the pressure-flow hypothesis (reviewed in De Schepper et al., 2013; Lucas et al., 2013). However, this idea is not fully supported as data demonstrating differential pressure between source and sink phloem has not been obtained (discussed in Knoblauch and Oparka, 2012). 
In addition to its role in resource allocation, the vasculature serves as an important conduit for the exchange of information between organs. Phloem sap appears to be highly complex, containing a diverse set of molecules such as sugars, lipids, amino acids, peptides, proteins, coding and non-coding RNAs, small molecules, mineral nutrients, and phytohormones (Lough and Lucas, 2006; Turgeon and Wolf, 2009; Lucas et al., 2013). By comparison, xylem sap appears to be less complex, primarily containing mineral nutrients, peptides, proteins, and hormones (Lucas et al., 2013; Turnbull and Lopez-Cobollo, 2013). Many of these molecules have been implicated as signals or signal chaperones in a number of developmental and stressrelated long-distance signaling pathways such as photoperiodinduced flowering, systemic acquired resistance (SAR), induced systemic resistance (ISR), wound responses, RNA silencing, autoregulation during plant-rhizobia symbioses, and systemic nutrient starvation responses. Most of these responses have been reviewed elsewhere (Lough and Lucas, 2006; Champigny and Cameron, 2009; Turgeon and Wolf, 2009; Lucas et al., 2013; Turnbull and Lopez-Cobollo, 2013; Lin et al., 2014), therefore we focus only on those that best illustrate how xylem and phloem facilitate inter-organ communication. The photoperiod-induced flowering response serves as the standard example for long-distance signaling in plants. Many plants sense increasing day length as a cue for the transition from vegetative to reproductive development. Early experiments demonstrated that a signal moves in the phloem from leaves, where day length is perceived, to the shoot apical meristem (SAM) where the transition to flowering is initiated (Zeevaart, 1976). More recent experiments identified the phloem-mobile signal as FT (FLOWERING LOCUS T) protein (Corbesier et al., 2007; Jaeger and Wigge, 2007). Interestingly, FT interacts with phospholipids that are important for FT's function in flowering-time regulation in the SAM (Nakamura et al., 2014). The lipid transfer protein DIR1 (DEFECTIVE IN INDUCED RESISTANCE 1) is an additional lipid-binding protein implicated in phloemmediated long-distance signaling. During the induction of SAR, DIR1 and phloem-mobile immune signals move from locally infected to naïve distant leaves to protect against future pathogen infection (Champigny and Cameron, 2009; Champigny et al., 2013). Several hydrophobic small molecules (azelaic acid, glycerol-3-phosphate, dehydroabietinal, pipecolic acid) have been identified as potential SAR mobile signals in the phloem; however, further experimentation is required to understand how these molecules participate in SAR (discussed in Dempsey and Klessig, 2012). Xylem-mediated long-distance signaling has been implicated in certain abiotic stress responses. For example, nutrient deprivation induces xylem-mobile hormone signals (cytokinins and strigolactones) that travel from roots to shoots to alter plant development (Lucas et al., 2013). Long-distance signaling responses sometimes utilize both xylem and phloem for signal movement. Following infection with symbiotic rhizobacteria, plants produce long-distance signals that travel through the xylem from roots to shoots to inform autotrophic tissues of the impending symbiotic association. Upon the perception of this xylem-borne signal, a shootgenerated signal accesses the phloem and travels back to the roots to regulate the development of symbiotic structures (Staehelin et al., 2011). Xylem-borne CLE (CLAVATA3/EMBRYO SURROUNDING REGION-RELATED) peptide signals from roots are believed to interact with LRR-RLKs (leucine rich repeat-receptor like kinases) in shoots, which in turn induce the accumulation and movement of unidentified shoot-derived signal(s) back to roots (Searle et al., 2003; Staehelin et al., 2011; Wang et al., 2016). Together, these responses illustrate how the plant vasculature acts a conduit for information sharing between distant tissues.

\section{Collecting Vascular Sap}

Our current understanding of vasculature-mediated longdistance signaling is impacted by the challenge of obtaining pure vascular sap. Standard methods involve collecting the fluid that exudes from the cut ends of petioles or puncture wounds of stems. Phloem sap is easily collected from cucurbits and legumes, which exude large amounts of phloem sap from petiole cut ends and stems (discussed in Turgeon and Wolf, 2009). Notably, the purity of cucurbit exudates has recently come into question, as some members of this family exude primarily from extrafascicular phloem (non-transport), and xylem (Zhang et al., 2010, 2012; Zimmerman et al., 2013). In other plants, phloem sap is collected over the course of several hours by submerging petiole ends in EDTA-containing solutions, which prevents sieve element occlusion by limiting the availability of $\mathrm{Ca}^{2+}$ (King and Zeevaart, 1974). While EDTA-facilitated exudation enables phloem sap collection from a wide variety of plants, the sample is substantially diluted during the process and prolonged exposure to EDTA may lead to intracellular (nonphloem) contamination caused by tissue softening. A recent improvement to this method was described by Guelette et al. (2012), who demonstrated that an initial 1-h incubation of Arabidopsis petioles in EDTA, followed by a 9-h exudation period in sterile water, was sufficient for metabolomics and proteomics analysis. Another technique for the collection of phloem sap is aphid stylectomy, which uses phloem-feeding insects as tools to collect pure sap directly from phloem cells (discussed in Turgeon and Wolf, 2009). While the collected phloem sap is much less dilute, collection volumes are low and the method is technically challenging.

Xylem sap is typically sampled from the cut stems of larger plants such as Brassica oleracea, Zea mays, and Glycine max via bleeding or root pressure techniques. Bleeding techniques sample xylem sap directly from the cut end of stems or petioles, while root pressure techniques apply pressure (mechanically or through positive pressure using ice) to the rootstock to force liquid through the xylem, which is then collected from the cut end of the stem (Alexou and Peuke, 2013). Despite measures such as the pre-washing and blotting of cut stems, contamination of xylem sap by phloem and/or other cellular contents can be an issue for most xylem sap collection methods (Alexou and Peuke, 2013). Since small proteins and peptides have been implicated in long-distance signaling in the xylem (Neumann, 2007; Lucas et al., 2013), Okamoto et al. (2015) recently optimized a gelfree purification technique to enrich for small proteins/peptides in xylem sap. Combining $o$-chlorophenol extractions and HPLC 
(high performance liquid chromatography) separation, the authors identified small proteins and peptides that were not detected using electrophoresis based-methods (Okamoto et al., 2015). However, a major limitation of these methods is the inability to collect xylem sap from smaller plants, which are often used as molecular-genetic model systems.

\section{PROTEOMICS ANALYSIS OF VASCULAR SAP}

Proteins play an important role in vasculature-mediated longdistance signaling responses, as demonstrated by the involvement of FT and DIR1 in photoperiod-induced flowering and SAR, respectively. Over the past 10 years, a number of proteomics studies provided information about the protein composition of xylem and phloem sap. Most studies relied on gel-based separation techniques such as $1 \mathrm{D}$ or 2D SDS-PAGE followed by standard protein detection approaches. This includes liquid chromatography (LC) coupled to mass spectrometers (MS), which consist of an ionization source (MALDI - matrix-assisted laser desorption/ionization, or ESI - electrospray ionization), and at least one of four types of mass analyzer; FTIC (fourier transform ion cyclotron), ion trap, TOF (time-of-flight), and quadrupole. Combinations of different mass analyzers in tandem MS set-ups improved protein coverage by overcoming particular weaknesses associated with each analyzer. In this review, we refer to these techniques simply as LC-MS/MS; for a comprehensive proteomics review, see Yates et al. (2009). Proteomics techniques have identified proteins in xylem and phloem sap collected from healthy plants growing in normal conditions (Table 1). In a recent review, Rodriguez-Celma et al. (2016) analyzed most of these studies and concluded that in general, the vascular fluids of multiple species contain proteins that appear to function in structural maintenance of the vasculature (e.g., cell wall metabolism) as well as constitutive defenses against pathogens (e.g., pathogenesis-related [PR] proteins, chitinases, proteases).

\section{COMPARATIVE PROTEOMICS ANALYSIS OF VASCULAR SAP}

Comparative proteomics of vascular sap is an excellent approach to identify proteins that may be involved in long-distance signaling responses. Early comparative proteomics studies relied on 1- or 2D difference gel electrophoresis (DIGE) techniques to compare the protein profiles of different samples. Spots present in some samples but not others are excised from the protein gel and analyzed by LC-MS/MS. Unfortunately, this type of analysis performs poorly with more complex samples, since individual proteins cannot be resolved by electrophoresis. Moreover, DIGE techniques have limited coverage since only differentially abundant proteins are analyzed (Gemperline et al., 2016). Modern gel-free comparative techniques overcome both of these issues while also providing quantitative information for every protein that is identified. Gel-free approaches such as
ICAT (isotope-coded affinity tag), ICPL (isotope-coded protein labeling), or iTRAQ (isobaric tags for relative and absolute quantitation) rely on the addition of chemical labels to protein samples. Alternatively, label-free comparative proteomics, in which separate MS runs are aligned and compared in silico, is used to identify differentially abundant proteins between samples/treatments. Label-free quantitation is much less labor intensive compared to label-dependent techniques such as iTRAQ, and often allows for superior protein detection and more accurate quantitation (Patel et al., 2009; Trinh et al., 2013). To date, each of these techniques has been successfully employed for comparative proteomics analysis of plant vascular sap during stress responses (Table 2). More detailed descriptions of these methods can be found in other reviews (Yates et al., 2009; Lottspeich and Kellermann, 2011).

\section{Comparative Proteomics Analysis of Xylem Sap}

Several comparative proteomics studies have been performed on xylem sap collected from plants experiencing stress (Table 2). The first was performed by Rep et al. (2002), who used MALDI-TOF-MS peptide fingerprinting to identify seven PRrelated proteins that accumulate in xylem sap of tomato (Solanum lycopersicum) plants infected with the xylem-infecting fungal pathogen Fusarium oxysporum. This finding was later supported by a 2D-DIGE proteomics study that identified host $\mathrm{PR}$ proteins as well as pathogen-derived proteins in tomato xylem sap during F. oxysporum infection (Houterman et al., 2007). Recently, more comprehensive analyses of xylem sap collected during host interactions with $F$. oxysporum were performed using label-free quantitative proteomics in tomato and Brassica oleracea (Gawehns et al., 2015; Pu et al., 2016). Both studies identified substantially more total proteins $(\sim 150-285)$ with a relatively high proportion of those proteins showing differential abundance during infection (Gawehns et al., 2015; Pu et al., 2016). Other xylem sap proteomes collected during plant-microbe interactions include Glycine max infected with Fusarium virguliforme (Abeysekara and Bhattacharyya, 2014), G. max during symbiosis with Bradyrhizobium japonicum or during treatment with elicitors from the pathogen Phytophthora sojae (Subramanian et al., 2009), and Brassica napus infected with Verticillium longisporum (Floerl et al., 2008). A common theme among these proteomes is the accumulation of $\mathrm{PR}$ proteins such as chitinases and glucanases, which may serve in an antimicrobial capacity to limit the spread of infection via xylem vessels (Sels et al., 2008).

Comparative proteomics analysis of xylem sap during abiotic stress has been studied in Zea mays, B. oleracea, and Gossypium hirsutum. Alvarez et al. (2008) analyzed xylem sap collected from well-watered and drought-stressed $Z$. mays using 2D-DIGE and LC-MS/MS, identifying 33 proteins that accumulated during drought and 8 that decreased in abundance. Fernandez-Garcia et al. (2011) analyzed xylem sap proteomes of salt-stressed and control B. oleracea plants 
TABLE 1 | Vascular sap proteomes of healthy plants.

\begin{tabular}{|c|c|c|c|}
\hline Species & Sap collection method & Number of proteins identified & Reference \\
\hline \multicolumn{4}{|c|}{ Xylem sap proteomes } \\
\hline \multirow[t]{2}{*}{ Brassica napus } & Root pressure & 10 & Buhtz et al., 2004 \\
\hline & Root pressure & 69 & Kehr et al., 2005 \\
\hline \multirow[t]{2}{*}{ Brassica oleracea } & Root pressure & 10 & Buhtz et al., 2004 \\
\hline & Bleed (stem) & 189 & Ligat et al., 2011 \\
\hline Cucurbita maxima & Root pressure & 11 & Buhtz et al., 2004 \\
\hline Cucumis sativus & Root pressure & 9 & Buhtz et al., 2004 \\
\hline \multirow[t]{2}{*}{ Glycine max } & Pressure (syringe) & $24^{1}$ & Djordjevic et al., 2007 \\
\hline & Pressure (syringe) & 16 & Krishnan et al., 2011 \\
\hline Gossypium hirsutum & Root pressure & $455^{2}$ & Zhang et al., 2015 \\
\hline Oryza sativa & Root pressure & 118 & Aki et al., 2008 \\
\hline Vitis vinifera & Bleed, pressure & 7 & Aguero et al., 2008 \\
\hline Zea mays & Root pressure & 59 & Alvarez et al., 2006 \\
\hline \multicolumn{4}{|c|}{ Phloem sap proteomes } \\
\hline \multirow[t]{2}{*}{ Arabidopsis thaliana } & EDTA-facilitated & 377 & Batailler et al., 2012 \\
\hline & EDTA-facilitated & 65 & Guelette et al., 2012 \\
\hline Brassica napus & Puncture & 140 & Giavalisco et al., 2006 \\
\hline \multirow[t]{4}{*}{ Cucurbita maxima } & Puncture & 29 & Walz et al., 2004 \\
\hline & Cut stem & 1121 & Lin et al., 2009 \\
\hline & Cut stem & 47 & Cho et al., 2010 \\
\hline & Cut stem/petioles & 320 & Frohlich et al., 2012 \\
\hline Cucumis melo & Cut stem/petioles & $14^{3}$ & Malter and Wolf, 2011 \\
\hline Cucumis sativus & Puncture & 16 & Walz et al., 2004 \\
\hline Hordeum vulgare & Stylectomy & 7 & Gaupels et al., 2008 \\
\hline Lupinus albus & Puncture & 86 & Rodriguez-Medina et al., 2011 \\
\hline Lupinus texensis & Puncture & 98 & Lattanzio et al., 2013 \\
\hline Oryza sativa & Stylectomy & 107 & Aki et al., 2008 \\
\hline Ricinus communis & Puncture & 18 & Barnes et al., 2004 \\
\hline
\end{tabular}

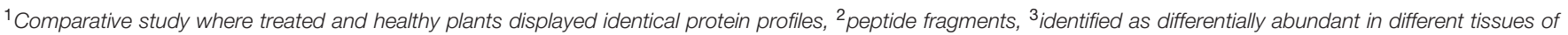
healthy plants.

using 2D-DIGE comparative proteomics, identifying 22 proteins that accumulated during salt stress and 18 proteins that decreased in abundance. More recent comparative proteomics analyses of xylem sap have focused on responses to nutrient limitation. Liao et al. (2012) analyzed the Z. mays xylem sap proteome during nitrogen-limiting and -oversupply conditions using 2-DIGE and Zhang et al. (2016) performed labelfree quantitative proteomics on xylem sap collected from cotton (G. hirsutum) seedlings grown under normal and potassium $(\mathrm{K})$-limited conditions. Interestingly, the differential abundance of PR proteins, proteases, redox-associated proteins, and cell wall metabolism proteins was observed in each of these studies (Alvarez et al., 2008; Fernandez-Garcia et al., 2011; Zhang et al., 2016), which hints at the importance of these proteins in the xylem during abiotic as well as biotic stress.

\section{Comparative Proteomics Analysis of Phloem Sap}

Comparative proteomics analysis of phloem sap has been performed to investigate long-distance signaling during a number of stress responses (Table 2). Using iTRAQ-based proteomics Du et al. (2015) analyzed phloem sap collected from resistant and susceptible rice (Oryza sativa) cultivars that were either unexposed or exposed to phloem-feeding brown plant hopper $(\mathrm{BPH})$ insects. They found that carbohydrate and protein metabolism proteins accumulated in phloem sap of susceptible $\mathrm{BPH}$-infested plants, and that defense-related proteins accumulated in BPH-resistant plants. Responses to virus infection were investigated using phloem sap collected from melon plants (Cucumis melo) that were uninfected or infected with melon necrotic spot virus (MNSV). Using 2D-DIGE and LC-MS/MS, the authors identified a number of cell-death and redox-associated proteins that were differentially abundant during infection with MNSV (Serra-Soriano et al., 2015). Lastly, a label-free quantitative proteomics study was recently undertaken by our group to identify differentially abundant proteins in phloem sap of Arabidopsis thaliana during the induction of SAR with virulent or avirulent strains of Pseudomonas syringae (Carella et al., 2016). Of the 564 proteins identified in Arabidopsis phloem sap, 16 accumulated and 46 decreased in abundance during SAR. Proteins that accumulated in phloem sap during SAR included PR-1, redox-associated proteins, and putative lipid-binding proteins, while proteins with decreased abundance were associated with metabolism. The functional relevance of these proteins was investigated by performing SAR assays 
TABLE 2 | Comparative proteomics studies of vascular sap collected during stress.

\begin{tabular}{|c|c|c|c|c|c|c|}
\hline Species & Treatment & $\begin{array}{l}\text { Comparative } \\
\text { method }\end{array}$ & $\begin{array}{c}\text { Total } \\
\text { proteins }\end{array}$ & $\begin{array}{l}\text { Increased } \\
\text { abundance }\end{array}$ & $\begin{array}{l}\text { Decreased } \\
\text { abundance }\end{array}$ & Reference \\
\hline \multicolumn{7}{|l|}{ Xylem sap } \\
\hline \multirow[t]{3}{*}{ Solanum lycopersicum } & Fusarium oxysporum & 1D-DIGE ${ }^{1}$ & $N / A^{2}$ & 7 & $N / A$ & Rep et al., 2002 \\
\hline & & 2D-DIGE & 33 & 25 & 0 & Houterman et al., 2007 \\
\hline & & Label-free $^{3}$ & 285 & 102 & 156 & Gawehns et al., 2015 \\
\hline Brassica oleracea & Fusarium oxysporum & Label-free & $155^{4} 204^{5}$ & $34^{4} 61^{5}$ & $78^{4} 104^{5}$ & Pu et al., 2016 \\
\hline \multirow[t]{3}{*}{ Glycine max } & Fusarium virguliforme & Presence/ Absence & 112 & $6^{6} 5^{7}$ & 5 & Abeysekara and Bhattacharyya, 2014 \\
\hline & Bradyrhizobium japonicum & 2D-DIGE & 19 & 4 & 3 & Subramanian et al., 2009 \\
\hline & Phytophthora sojae elicitor & & & 2 & 0 & \\
\hline Brassica napus & Verticillium longisporum & 1D-DIGE & $\mathrm{N} / \mathrm{A}$ & 3 & $\mathrm{~N} / \mathrm{A}$ & Floerl et al., 2008 \\
\hline \multirow[t]{2}{*}{ Zea mays } & Drought & 2D-DIGE & 39 & 33 & 8 & Alvarez et al., 2008 \\
\hline & N-supply & 2D-DIGE & 23 & 14 & 9 & Liao et al., 2012 \\
\hline Brassica oleracea & $\mathrm{NaCl}$ & 2D-DIGE & 40 & 22 & 18 & Fernandez-Garcia et al., 2011 \\
\hline Gossypium hirsutum & K-limitation & Label-free & $285^{8}$ & 5 & 41 & Zhang et al., 2016 \\
\hline \multicolumn{7}{|l|}{ Phloem sap } \\
\hline Hybrid Poplar & Wounding & 2D-DIGE & 48 & 2 & 0 & Dafoe et al., 2009 \\
\hline Cucurbita maxima & Wounding & $\mathrm{ICPL}^{9}$ & 300 & $25^{10} 39^{11}$ & $26^{10} 12^{11}$ & Gaupels et al., 2012 \\
\hline Cucumis sativus & $\mathrm{NaCl}$ & iTRAQ $^{12}$ & 745 & $25^{13} 12^{14}$ & $44^{13} 53^{14}$ & Fan et al., 2015 \\
\hline Brassica napus & Fe-limitation & 2D-DIGE & $263^{15}$ & 19 & 22 & Gutierrez-Carbonell et al., 2015 \\
\hline Oryza sativa & Brown Planthopper & iTRAQ & 238 & $8^{16} 10^{17}$ & $26^{16} 13^{17}$ & Du et al., 2015 \\
\hline Cucumis melo & Melon Necrotic Spot Virus & 2D-DIGE & $1046^{15}$ & 13 & 9 & Serra-Soriano et al., 2015 \\
\hline Arabidopsis thaliana & Pseudomonas syringae & Label-free & 564 & 16 & 46 & Carella et al., 2016 \\
\hline
\end{tabular}

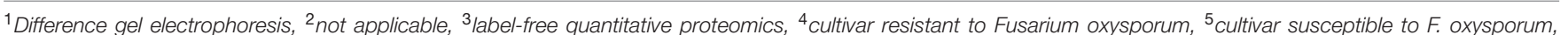

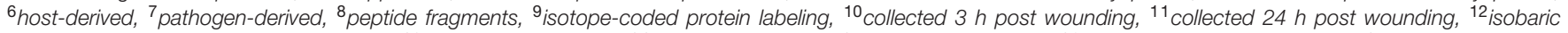

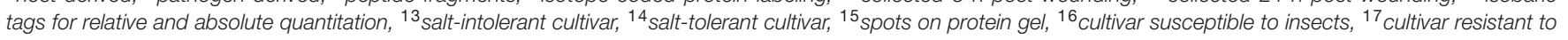
insects.

on corresponding T-DNA knockout mutants, which identified m-type thioredoxins (TRXm1 and TRXm4) and a major latex protein (MLP) as novel phloem-localized proteins that play functional roles in SAR.

Comparative proteomics analyses of phloem sap collected during abiotic stress responses have also been performed. An initial comparative study of phloem sap collected from hybrid poplar (healthy or mechanically wounded) identified 48 total proteins using 2D-DIGE and LC-MS/MS, with two proteins accumulating during wounding stress (Dafoe et al., 2009). A subsequent ICPL-based study of phloem sap collected from wounded and unwounded cucumber (Cucumis sativus) identified substantially more total and differentially abundant proteins (Gaupels et al., 2012). Interestingly, PR-type proteins were identified in the phloem sap of poplar and cucumber (Dafoe et al., 2009; Gaupels et al., 2012) and cucumber phloem also contained cyclophilins, carbon metabolism-related proteins, and other defenserelated proteins (Gaupels et al., 2012). The phloem sap proteomes of plants experiencing other types of abiotic stress have been investigated in cucumber and B. napus. An iTRAQ-based study of phloem sap collected from salt-stressed cucumber identified several salt-responsive phloem proteins in salt-tolerant and -intolerant cultivars (Fan et al., 2015). In addition, comparative 2D-DIGE and LC-MS/MS analysis of phloem sap collected from Fe-deficient and control B. napus plants identified a number of redox-associated proteins with differential abundance during Fe stress (Gutierrez-Carbonell et al., 2015).

\section{Common Proteins Present in Vascular Sap Proteomes during Stress}

Comparative proteomics analysis of vascular sap has revealed a great deal about how the vascular system responds to stress. Surprisingly, a common theme among many xylem and phloem sap proteomes collected from stressed plants is the accumulation of $\mathrm{PR}$ proteins including thaumatin-like proteins, chitinases, glucanases, and MLPs. This may indicate that PR proteins play a role in the protection of the vasculature against pathogen/herbivore attack. Redox-related proteins (thioredoxins, peroxidases, etc.) are similarly associated with stress responses in the vasculature. It has been proposed that these proteins play a protective role in the phloem by preventing damage to proteins caused by oxidative stress (Walz et al., 2002). This may be especially important in phloem sieve elements as these cells lack protein synthesis machinery and cannot quickly replace proteins damaged during stress. In addition, cyclophilins, glycine-rich proteins (GRPs), and putative lipidbinding proteins are commonly identified in both xylem and phloem sap proteomes. The identification of multiple lipidbinding proteins in vascular sap supports the idea of lipid-based long-distance signaling in the vasculature (Benning et al., 2012; Barbaglia et al., 2016). The role of cyclophilins and GRPs in the vasculature is less clear. Extracellular GRPs have been linked to 
cell wall formation, while intracellular GRPs and cyclophilins have been implicated in a number of functions including RNAbinding/chaperoning, which may suggest a role in RNA-mediated long-distance signaling in the vasculature (Mangeon et al., 2010; Kumari et al., 2013; Rodriguez-Celma et al., 2016).

\section{CONCLUSION AND FUTURE DIRECTIONS}

The emergence of sophisticated proteomics techniques has led to a new era in vascular sap proteomics studies. Together, these studies provide fundamental insights into the nature of plant vascular sap under normal and stress conditions. Although significant progress has been made in this field, much remains to be discovered. Further improvements to existing proteomics techniques will make it possible to detect lowabundance proteins essential for vasculature function. Moreover, novel xylem sap collection protocols for genetically tractable model systems are needed to investigate the importance of xylem-mobile proteins at the molecular-genetic level. In the

\section{REFERENCES}

Abeysekara, N. S., and Bhattacharyya, M. K. (2014). Analyses of the xylem sap proteomes identified candidate Fusarium virguliforme proteinacious toxins. PLoS ONE 9:e93667. doi: 10.1371/journal.pone.0093667

Aguero, C. B., Thorne, E. T., Ibanez, A. M., Gubler, W. D., and Dandekar, A. M. (2008). Xylem sap proteins from Vitis vinifera L. chardonnay. Am. J. Enol. Vitic. 59, 306-311.

Aki, T., Shigyo, M., Nakano, R., Yoneyama, T., and Yanagisawa, S. (2008). Nanoscale proteomics revealed the presence of regulatory proteins inclusing three FT-like proteins in phloem and xylem saps from rice. Plant Cell Physiol. 49, 767-790. doi: 10.1093/pcp/pcn049

Alexou, M., and Peuke, A. D. (2013). "Methods for xylem sap collection," in Plant Mineral Nutrients: Methods and Protocols, Methods in Molecular Biology, Vol. 953, ed. F. J. M. Maathuis (New York, NY: Humana Press), 195-207.

Alvarez, S., Goodger, J. Q. D., Marsh, E. L., Chen, S., Asirvatham, V. S., and Schachtman, D. P. (2006). Characterization of the maize xylem sap proteome. J. Proteome Res. 5, 963-972. doi: 10.1021/pr050471q

Alvarez, S., Marsh, E. L., Schroeder, S. G., and Schachtman, D. P. (2008). Metabolic and proteomic changes in the xylem sap of maize under drought. Plant Cell Environ. 31, 325-340. doi: 10.1111/j.1365-3040.2007.01770.x

Barbaglia, A. M., Tamot, B., Greve, V., and Hoffmann-Benning, S. (2016). Phloem proteomics reveals new lipid-binding proteins with a putative role in lipidmediated signaling. Front. Plant Sci. 7:563. doi: 10.3389/fpls.2016.00563

Barnes, A., Bale, J., Constantinidou, C., Ashton, P., Jones, A., and Pritchard, J. (2004). Determining protein identity from sieve element sap in Ricinus communis L. by quadrupole time of flight (Q-TOF) mass spectrometry. J. Exp. Bot. 55, 1473-1481. doi: 10.1093/jxb/erh161

Batailler, B., Lemaitre, T., Vilaine, F., Sanchez, C., Renard, D., Cayla, T., et al. (2012). Soluble and filamentous proteins in Arabidopsis sieve elements. Plant Cell Environ. 35, 1258-1273. doi: 10.1111/j.1365-3040.2012.02487.x

Benning, U. F., Tamot, B., Guelette, B. S., and Hoffmann-Benning, S. (2012). New aspects of phloem-mediated long-distance lipid signaling in plants. Front. Plant Sci. 3:53. doi: 10.3389/fpls.2012.00053

Buhtz, A., Kolasa, A., Arlt, K., Walz, C., and Kehr, J. (2004). Xylem sap protein composition is conserved among different plant species. Planta 219, 610-618. doi: 10.1007/s00425-004-1259-9

Carella, P., Merl-Pham, J., Wilson, D. C., Dey, S., Hauck, S. M., Vlot, A. C., et al. (2016). Comparative proteomics analysis of Arabidopsis phloem exudates collected during the induction of systemic acquired resistance. Plant Physiol. doi: $10.1104 /$ pp. 16.00269 meantime, researchers can take advantage of the Arabidopsis model system and the recently improved Arabidopsis phloem sap collection method (Guelette et al., 2012; Tetyuk et al., 2013) to expand our understanding of the molecular mechanisms of phloem-mediated long-distance signaling during plant stress.

\section{AUTHOR CONTRIBUTIONS}

Conceived of the review: PC and RC. Wrote the review: PC, DW, and RC. Analyzed literature and created tables: PC and CK. All authors edited the manuscript.

\section{FUNDING}

This research was funded by a Natural Sciences and Engineering Research Council of Canada (NSERC) grant to RC, an NSERC graduate scholarship to DW, and an Ontario Graduate Scholarship to PC.

Champigny, M. J., and Cameron, R. K. (2009). “Action at a distance: long- distance signals in induced resistance," in Plant Innate Immunity, Vol. 51, ed. L. C. Van Loon (London: Academic Press), 123-171.

Champigny, M. J., Isaacs, M., Carella, P., Faubert, J., Fobert, P., and Cameron, R. K. (2013). Long distance movement of DIR1 and investigation of the role of DIR1like during systemic acquired resistance in Arabidopsis. Front. Plant Sci. 4:230. doi: 10.3389/fpls.2013.00230

Cho, W. K., Chen, X.-Y., Rim, Y., Chu, H., Kim, S., Kim, S.-W., et al. (2010). Proteome study of the phloem sap of pumpkin using multidimensional protein identification technology. J. Plant Physiol. 167, 771-778. doi: 10.1016/j.jplph.2010.01.004

Corbesier, L., Vincent, C., Jang, S., Fornara, F., Fan, Q., Searle, I., et al. (2007). FT protein movement contributes to long-distance signaling in floral induction of Arabidopsis. Science 316, 1030-1033. doi: 10.1126/science.1141752

Dafoe, N. J., Zamani, A., Ekramoddoullah, A. K. M., Lippert, D., Bohlmann, J., and Constabel, C. P. (2009). Analysis of the poplar phloem proteome and its response to leaf wounding. J. Proteome Res. 8, 2341-2350. doi: $10.1021 /$ pr800968r

De Schepper, V., De Swaef, T., Bauweraerts, I., and Steppe, K. (2013). Phloem transport: a review of mechanisms and controls. J. Exp. Bot. 64, 4839-4850. doi: $10.1093 /$ jxb/ert302

Dempsey, D. A., and Klessig, D. F. (2012). SOS - too many signals for systemic acquired resistance? Trends Plant Sci. 17, 538-545. doi: 10.1016/j.tplants.2012.05.011

Djordjevic, M. A., Oakes, M., Li, D. X., Hwang, C. H., Hocart, C. H., and Gresshoff, P. M. (2007). The Glycine max xylem sap and apoplast proteome. J. Proteome Res. 6, 3771-3779. doi: 10.1021/pr0606833

Du, B., Wei, Z., Wang, Z., Wang, X., Peng, X., Du, B., et al. (2015). Phloem-exudate proteome analysis of response to insect brown plant-hopper in rice. J. Plant Physiol. 183, 13-22. doi: 10.1016/j.jplph.2015.03.020

Fan, H., Xu, Y., Du, C., and Wu, X. (2015). Phloem sap proteome studied by iTRAQ provides integrated insight into salinity response mechanisms in cucumber plants. J. Proteomics 125, 54-67. doi: 10.1016/j.jprot.2015.05.001

Fernandez-Garcia, N., Hernandez, M., Casado-Vela, J., Bru, R., Elortza, F., Hedden, P., et al. (2011). Changes to the proteome and targeted metabolites of xylem sap in Brassica oleracea in response to salt stress. Plant Cell Environ. 34, 821-836. doi: 10.1111/j.1365-3040.2011.02285.x

Floerl, S., Druebert, C., Majcherczyk, A., Karlovsky, P., Kues, U., and Polle, A. (2008). Defense reactions in the apoplastic proteome of oilseed rape (Brassica napus var. napus) attenuate Verticillium longisporum growth but not disease symptoms. BMC Plant Biol. 8:129. doi: 10.1186/1471-2229-8-129 
Frohlich, A., Gaupels, F., Sarioglu, H., Holzmeister, C., Spannagl, M., Durner, J., et al. (2012). Looking deep inside: detection of low abundance proteins in leaf extracts of Arabidopsis and phloem exudates of pumpkin. Plant Physiol. 159, 902-914. doi: 10.1104/pp.112.198077

Gaupels, F., Buhtz, A., Knauer, T., Deshmukh, S., Waller, F., van Bel, A. J. E., et al. (2008). Adaptation of aphid stylectomy for analyses of proteins and mRNAs in barley phloem sap. J. Exp. Bot. 59, 3297-3306. doi: 10.1093/jxb/ern181

Gaupels, F., Sarioglu, H., Beckmann, M., Hause, B., Spannagl, M., Draper, J., et al. (2012). Deciphering systemic wound responses of the pumpkin extrafascicular phloem by metabolomics and stable isotope-coded protein labeling. Plant Physiol. 160, 2285-2299. doi: 10.1104/pp.112.205336

Gawehns, F., Ma, L., Bruning, O., Houterman, P. K., Boeren, S., Cornelissen, B. J. C., et al. (2015). The effector repertoire of Fusarium oxysporum determines the tomato xylem proteome composition following infection. Front. Plant Sci. 6:967. doi: 10.3389/fpls.2015.00967

Gemperline, E., Keller, C., and Li, L. (2016). Mass spectrometry in plant-omics. Anal. Chem. doi: 10.1021/acs.analchem.5b02938

Giavalisco, P., Kapitza, K., Kolasa, A., Buhtz, A., and Kehr, J. (2006). Towards the proteome of Brassica napus phloem sap. Proteomics 6, 896-909. doi: 10.1002/pmic. 200500155

Guelette, B. S., Benning, U. F., and Hoffmann-Benning, S. (2012). Identification of lipids and lipid-binding proteins in phloem exudates of Arabidopsis thaliana. J. Exp. Bot. 63, 3603-3616. doi: 10.1093/jxb/ers028

Gutierrez-Carbonell, E., Lattanzio, G., Albacete, A., Ruiz, J. J. R., Kehr, J., Abadia, A., et al. (2015). Effects of Fe deficiency on the protein profile of Brassica napus phloem sap. Proteomics 15, 3835-3853. doi: 10.1002/pmic.201400464

Houterman, P. M., Speijer, D., Dekker, H. L., De Koster, C. G., Cornelissen, B. J. C., and Rep, M. (2007). The mixed xylem proteome of Fusarium oxysporuminfected tomato plants. Mol. Plant Pathol. 8, 215-221. doi: 10.1111/J.13643703.2007.00384.X

Jaeger, K. E., and Wigge, P. A. (2007). FT protein acts as a long-range signal in Arabidopsis. Curr. Biol. 17, 1050-1054. doi: 10.1016/j.cub.2007.05.008

Kehr, J., Buhtz, A., and Giavalisco, P. (2005). Analysis of xylem sap proteins from Brassica napus. BMC Plant Biol. 5:11. doi: 10.1186/1471-2229-5-11

King, R. W., and Zeevaart, J. A. D. (1974). Enhancement of phloem exudation from cut petioles by chelating agents. Plant Physiol. 53, 96-103. doi: 10.1104/pp.53.1.96

Knoblauch, M., and Oparka, K. (2012). The structure of the phloem-still more questions than answers. Plant J. 70, 147-156. doi: 10.1111/j.1365313X.2012.04931.x

Krishnan, H. B., Natarajan, S. S., Bennett, J. O., and Sicher, R. C. (2011). Protein and metabolite composition of xylem sap from field-grown soybeans (Glycine max). Planta 233, 921-931. doi: 10.1007/s00425-011-1352-9

Kumari, S., Roy, S., Singh, P., Singla-Pareek, S. L., and Pareek, A. (2013). Cyclophilins: proteins in search of function. Plant Signal. Behav. 8:e22734. doi: $10.4161 /$ psb. 22734

Lattanzio, G., Andaluz, S., Matros, A., Celvete, J. J., Kehr, J., Abadia, A., et al. (2013). Protein profile of Lupinus texensis phloem sap exudates: searching for Fe- and $\mathrm{Zn}$-containing proteins. Proteomics 13, 2283-2296. doi: 10.1002/pmic.201200515

Liao, C., Liu, R., Zhang, F., Li, C., and Li, X. (2012). Nitrogen under-and oversupply induces distinct protein responses in maize xylem sap. J. Integr. Plant Biol. 54, 374-387. doi: 10.1111/j.1744-7909.2012.01122.x

Ligat, L., Lauber, E., Albenne, C., San Clemente, H., Valot, B., Zivy, M., et al. (2011). Analysis of the xylem sap proteome of Brassica oleracea reveals a high content in secreted proteins. Proteomics 11, 1798-1813. doi: 10.1002/pmic.20100078

Lin, M.-K., Lee, Y.-J., Lough, T. J., Phinney, B. S., and Lucas, W. J. (2009). Analysis of the pumpkin phloem proteome provides insights into angiosperm sieve tube function. Mol. Cell. Proteomics 8, 343-356. doi: 10.1074/mcp.M800420MCP200

Lin, W.-Y., Huang, T.-K., Leong, S. J., and Chiou, T.-J. (2014). Long-distance call from phosphates: systemic regulation of phosphate starvation responses. J. Exp. Bot. 65, 1817-1827. doi: 10.1093/jxb/ert431

Lottspeich, F., and Kellermann, J. (2011). "ICPL labeling strategies for proteome research," in Gel-Free Proteomics, Methods in Molecular Biology, Vol. 753, eds K. Gevaert and J. Vandekerckhove (New York, NY: Humana Press), 55-64. doi: 10.1007/978-1-61779-148-2
Lough, T. J., and Lucas, W. J. (2006). Integrative plant biology: role of phloem longdistance macromolecular trafficking. Annu. Rev. Plant Biol. 57, 203-232. doi: 10.1146/annurev.arplant.56.032604.144145

Lucas, W. J., Groover, A., Lichtenberger, R., Furuta, K., Yadav, S.-R., Helariutta, Y., et al. (2013). The plant vascular system: evolution, development and functions. J. Int. Plant Biol. 55, 294-388. doi: 10.1111/jipb.12041

Malter, D., and Wolf, S. (2011). Melon phloem-sap proteome: developmental control and response to viral infection. Protoplasma 248, 217-224. doi: 10.1007/s00709-010-0215-8

Mangeon, A., Junqueira, R. M., and Sachetto-Martins, G. (2010). Functional diversity of the plant glycine-rich proteins superfamily. Plant Signal. Behav. 5, 99-104. doi: 10.4161/psb.5.2.10336

Nakamura, Y., Andres, F., Kanehara, K., Liu, Y.-C., Dormann, P., and Coupland, G. (2014). Arabidopsis florigen FT binds to diurnally oscillating phospholipids that accelerate flowering. Nat. Comm. 5:3553. doi: 10.1038/ncomms 4553

Neumann, P. M. (2007). Evidence for long-distance xylem transport of signal peptide activity from tomato roots. J. Exp. Bot. 58, 2217-2223. doi: 10.1093/jxb/erm081

Okamoto, S., Suzuki, T., Kawaguchi, M., Higashiyama, T., and Matsubayashi, Y. (2015). A comprehensive strategy for identifying long-distance mobile peptides in xylem sap. Plant J. 84, 611-620. doi: 10.1111/tpj.13015

Patel, V. J., Thalassinos, K., Slade, S., Connolly, J. B., Crombie, A., Murrell, J. C., et al. (2009). A comparison of labeling and label-free mass spectrometrybased proteomics approaches. J. Proteome Res. 8, 3752-3759. doi: 10.1021/pr90 0080y

Pu, Z., Ino, Y., Kimura, Y., Tago, A., Shimizu, M., Natsume, S., et al. (2016). Changes in the proteome of xylem sap in Brassica oleracea in response to Fusarium oxysporum stress. Front. Plant Sci. 7:31. doi: 10.3389/fpls.2016. 00031

Rep, M., Dekker, H. L., Vossen, J. H., de Boer, A. D., Houterman, P. M., Speijer, D., et al. (2002). Mass spectrometric identification of isoforms of PR proteins in xylem sap of fungus-infected tomato. Plant Physiol. 130, 904-917. doi: 10.1104/pp.007427

Rodriguez-Celma, J., Ceballos-Laita, L., Grusak, M. A., Abadia, J., and LopezMillan, A.-F. (2016). Plant fluid proteomics: delving into the xylem sap, phloem sap and apoplastic fluid proteomics. Biochim Biophys Acta doi: 10.1016/j.bbapap.2016.03.014 [Epub ahead of print].

Rodriguez-Medina, C., Atkins, C. A., Mann, A. J., Jordan, M. E., and Smith, P. M. C. (2011). Macromolecular composition of phloem exudate from white lupin (Lupinus albus L.). BMC Plant Biol. 11:36. doi: 10.1186/1471-222 9-11-36

Searle, I. R., Men, A. E., Laniya, T. S., Buzas, D. M., Iturbe-Ormaetxe, I., Carroll, B. J., et al. (2003). Long-distance signaling in nodulation directed by a CLAVATA1-like receptor kinase. Science 299, 109-112. doi: $10.1126 /$ science. 1077937

Sels, J., Mathys, J., De Coninck, B. M. A., Cammue, B. P. A., and De Bolle, M. F. C. (2008). Plant pathogenesis-related (PR) proteins: a focus on PR peptides. Plant Physiol. Biochem. 46, 941-950. doi: 10.1016/j.plaphy.2008. 06.011

Serra-Soriano, M., Navarro, J. A., Genoves, A., and Pallas, V. (2015). Comparative proteomic analysis of melon phloem exudates in response to viral infection. J. Proteomics 124, 11-24. doi: 10.1016/j.jprot.2015.04.008

Staehelin, C., Xie, Z.-P., Illana, A., and Vierheilig, H. (2011). Long-distance transport of signals during symbiosis: are nodule formation and mycorrhization autoregulated in a similar way. Plant Signal. Behav. 6, 373-377. doi: $10.4161 /$ psb.6.3.13881

Subramanian, S., Cho, U.-H., Keyes, C., and Yu, O. (2009). Distinct changes in soybean xylem sap proteome in response to pathogenic and symbiotic microbe interactions. BMC Plant Biol. 9:119. doi: 10.1186/1471-2229-9-119

Tetyuk, O., Benning, U. F., and Hoffmann-Benning, S. (2013). Collection and analysis of Arabidopsis phloem exudates using the EDTA-facilitated method. J. Vis. Exp. 80:e51111. doi: 10.3791/51111

Trinh, H. V., Grossmann, J., Gehrig, P., Roschitzki, B., Schlapbach, R., Greber, U. F., et al. (2013). iTRAQ-based and label-free proteomic approaches for studies of human adenovirus infections. Int. J. Proteomics 2013:581862. doi: $10.1155 / 2013 / 581862$ 
Turgeon, R., and Wolf, W. (2009). Phloem transport: cellular pathways and molecular trafficking. Annu. Rev. Plant Biol. 60, 207-221. doi: 10.1146/annurev.arplant.043008.092045

Turnbull, C. G. N., and Lopez-Cobollo, R. M. (2013). Heavy traffic in the fast lane: long-distance signalling by macromolecules. New Phytol. 198, 33-51. doi: 10.1111/nph.12167

Walz, C., Giavalisco, P., Schad, M., Juenger, M., Kloze, J., and Kehr, J. (2004). Proteomics of cucurbit phloem exudate reveals a network of defence proteins. Phytochemistry 65, 1795-1804. doi: 10.1016/j.phytochem.2004. 04.006

Walz, C., Juenger, M., Schad, M., and Kehr, J. (2002). Evidence for the presence and activity of a complete antioxidant defence system in mature sieve tubes. Plant J. 31, 189-197. doi: 10.1046/j.1365-313X.2002.01348.x

Wang, G., Zhang, G., and Wu, M. (2016). CLE peptide signaling and crosstalk with phytohormones and environmental stimuli. Front. Plant Sci. 6:1211. doi: 10.3389/fpls.2015.01211

Yates, J. R., Ruse, C. I., and Nakorchevsky, A. (2009). Proteomics by mass spectrometry: approaches, advances, and applications. Annu. Rev. Biomed. Eng. 11, 49-79. doi: 10.1146/annurev-bioeng-061008124934

Zeevaart, J. A. D. (1976). Physiology of flower formation. Annu. Rev. Plant Physiol. 27, 321-348. doi: 10.1146/annurev.pp.27.060176.001541

Zhang, B., Tolstikov, V., Turnbull, C., Hicks, L. M., and Fiehn, O. (2010). Divergent metabolome and proteome suggest functional independence of dual transport systems in cucurbits. Proc. Natl. Acad. Sci. U.S.A. 107, 13532-13537. doi: 10.1073/pnas.0910558107
Zhang, C., Yu, X., Ayre, B. G., and Turgeon, R. (2012). The origin and composition of cucurbit "phloem" exudate. Proc. Natl. Acad. Sci. U.S.A. 158, 1878-1882. doi: 10.1104/pp.112.194431

Zhang, Z., Chao, M., Wang, S., Bu, J., Tang, J., Li, F., et al. (2016). Proteome quantification of cotton xylem sap suggests the mechanisms of potassiumdeficiency-induced changes in plant resistance to environmental stresses. Sci. Rep. 6:21060. doi: 10.1038/srep21060

Zhang, Z., Xin, W., Wang, S., Zhang, X., Dai, H., Sun, R., et al. (2015). Xylem sap in cotton contains proteins that contribute to environmental stress response and cell wall development. Funct. Integr. Genomics 15, 17-26. doi: 10.1007/s10142014-0395-y

Zimmerman, M. R., Hafke, J. B., van Bel, A. J. E., and Furch, A. C. U. (2013). Interaction of xylem and phloem during exudation and wound occlusion in Cucurbita maxima. Plant Cell Environ. 36, 237-247. doi: 10.1111/j.13653040.2012.02571.x

Conflict of Interest Statement: The authors declare that the research was conducted in the absence of any commercial or financial relationships that could be construed as a potential conflict of interest.

Copyright (C) 2016 Carella, Wilson, Kempthorne and Cameron. This is an open-access article distributed under the terms of the Creative Commons Attribution License (CC BY). The use, distribution or reproduction in other forums is permitted, provided the original author(s) or licensor are credited and that the original publication in this journal is cited, in accordance with accepted academic practice. No use, distribution or reproduction is permitted which does not comply with these terms. 